\title{
A simple and widely available alternative method for endotracheal tube cuff pressure monitoring
}

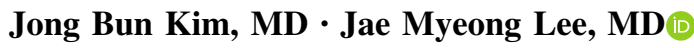

Received: 24 January 2018/Revised: 21 February 2018/ Accepted: 22 February 2018/Published online: 22 March 2018

(C) Canadian Anesthesiologists' Society 2018

\section{To the Editor,}

We read the report by Miao et al. ${ }^{1}$ suggesting that a simple method is needed for monitoring endotracheal tube (ETT) cuff pressure and herein present such a method.
We use a conventional invasive blood pressure monitor transducer to continuously display the ETT cuff pressure on the anesthetic monitoring system (Figure). As anesthesiologists already focus on vital signs in daily
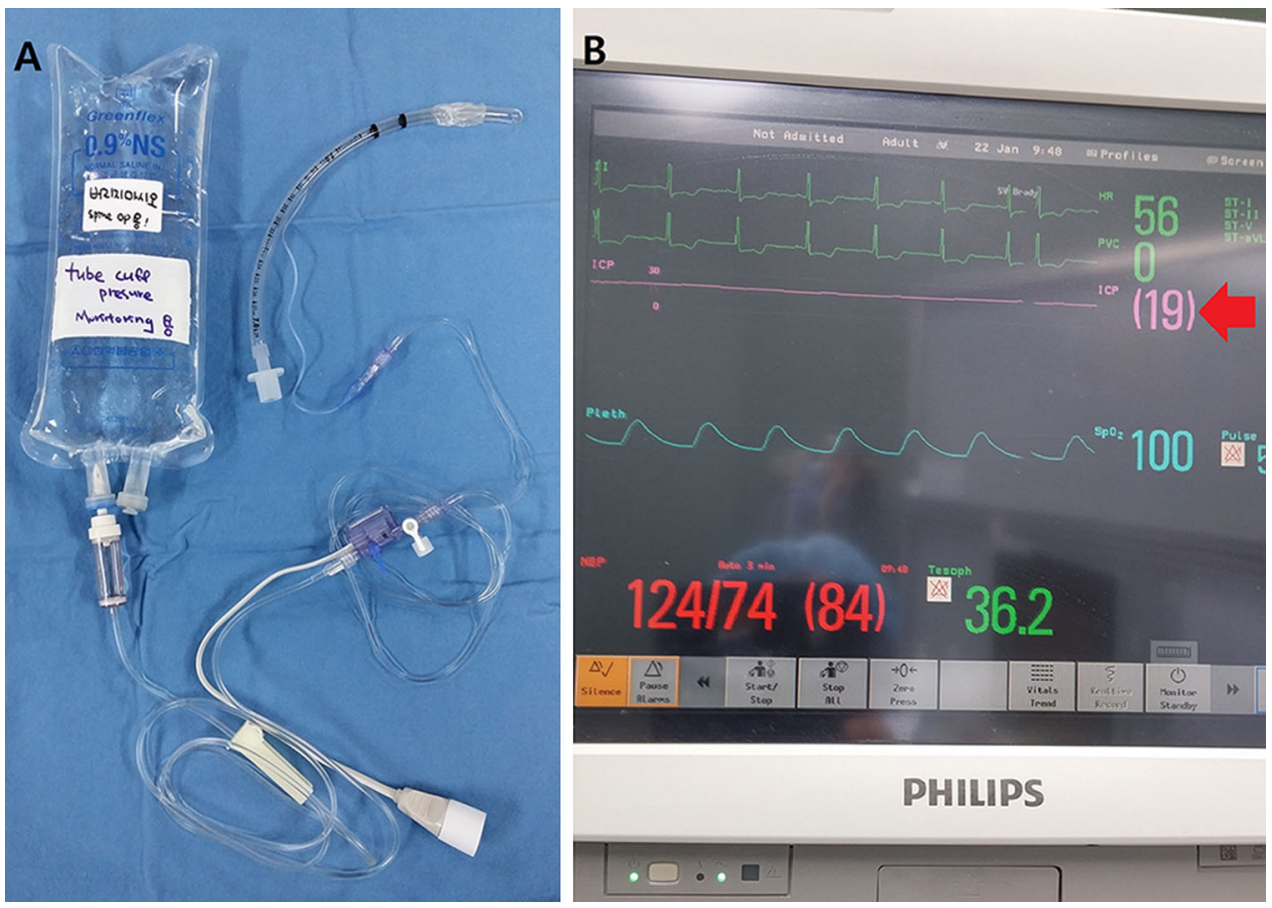

Figure A) The pressure monitor transducer system that can be connected to the endotracheal cuff pilot balloon (no inflatable pressure bag is needed). B) Endotracheal cuff pressure (red arrow) can measure continuously and be displayed on the anesthetic monitor

J. B. Kim, MD · J. M. Lee, MD (ه)

Department of Anaesthesiology and Pain Medicine, Uijeongbu

St. Mary's Hospital, College of Medicine, The Catholic

University of Korea, Seoul, Republic of Korea

e-mail: jaemng@catholic.ac.kr 
practice, measuring the ETT cuff pressure would be an easy addition for the same monitoring. This would overcome the inconvenience of intermittently using a manual pressure gauge and if the pressure measurement were out of range, it would be easier to see and could have an alarm set to alert the anesthesiologist to the maximum and minimum cuff pressures. Ganigara et al. reported on continuous real-time ETT cuff pressure monitoring ${ }^{2}$ and correlations of pressure between the manometer and a standard invasive pressure monitoring device were assessed by Krishna et $a l^{3}$ Pressure is displayed in $\mathrm{mmHg}$, which should be converted to $\mathrm{cmH}_{2} \mathrm{O}$ ( $1 \mathrm{cmH}_{2} \mathrm{O} \approx 0.74 \mathrm{mmHg}$ ), and appropriate cuff pressures are between 20 and $30 \mathrm{cmH}_{2} \mathrm{O}$; these can be converted to $15-22 \mathrm{mmHg}$. The process adds minimal cost as the system can easily be re-used, and it limits the complications related to high cuff pressure. ${ }^{4}$

This technique may be particularly useful for cervical spine and otolaryngologic surgeries when the ETT is too remote from the anesthesiologists and it is difficult to use manual hand-held manometers. Furthermore, in cervical spine and otolaryngologic surgeries, the trachea is frequently compressed, and many complications are reported. ${ }^{4}$ Pressure monitors are very necessary, but paradoxically, it is more difficult during these surgeries to monitor ETT cuff pressure.
We thus recommend that our colleagues use this simple, inexpensive monitor in daily practice.

Financial disclosures None.

Conflicts of interest None declared.

Editorial responsibility This submission was handled by Dr. Hilary P. Grocott, Editor-in-Chief, Canadian Journal of Anesthesia.

Editor's note The authors of the article: Can J Anesth 2018; https:// doi.org/10.1007/12630-018-1053-y, respectfully declined an invitation to submit a reply to the above letter.

\section{References}

1. Miao I, Jee R, Pysyk CL. Under pressure: an audit of airway device pressures. Can J Anesth 2018. DOI: https://doi.org/10.1007/ s12630-018-1053-y.

2. Ganigara A, Ramavakoda C. Continuous real time endotracheal tube cuff pressure waveform. J Clin Monit Comput 2014; 28: 433-4.

3. Krishna $S$, Ramesh A, Jatana $K$, et al. A technique to measure the intracuff pressure continuously: an in vivo demonstration of its accuracy. Paediatr Anaesth 2014; 24: 999-1004.

4. Kako H, Goykhman A, Ramesh AS, Krishna SG, Tobias JD. Changes in intracuff pressure of a cuffed endotracheal tube during prolonged surgical procedures. Int $\mathrm{J}$ Pediatr Otorhinolaryngol 2015; 79: 76-9. 